\title{
Diverticulitis aguda perforada simulando prostatitis aguda*
}

\author{
Drs. JAIME RUIZ-TOVAR ${ }^{1}$, CARLOS GAMALLO² \\ Servicio de Cirugía General. Hospital Universitario Ramón y Cajal. Madrid, España. \\ 2 Servicio de Anatomía Patológica Hospital Universitario La Princesa. Madrid, España.
}

\begin{abstract}
\section{Perforated acute diverticulitis mimicking acute prostatitis}

We present an unfrequent case of acute diverticulitis mimmicking acute prostatitis. Case report: A 72-year-old man suffering from hypogastric and genital pain, fever and dysuria, with an edematous and tender prostate at physical examination, was initially diagnosed of acute prostatitis. 24 hours later the patient developed left lower quadrant pain and abdominal distension. A CT scan was performed, showing pneumoperitoneum and acute sigmoid diverticulitis signs. The patient underwent a Hartmann's procedure.
\end{abstract}

Key words: Acute prostatitis, acute diverticulitis, urologic symptoms.

\section{Resumen}

Presentamos un caso infrecuente de diverticulitis aguda con manifestaciones clínicas sugerentes de prostatitis aguda. Caso clínico: Varón de 72 años, presenta dolor hipogástrico y en región genital, fiebre y disuria, palpándose una próstata edematosa y dolorosa al tacto rectal, por lo que es inicialmente diagnosticado de prostatitis aguda. A las 24 horas el paciente desarrolla un cuadro de distensión abdominal y dolor en fosa ilíaca izquierda. Una TC abdominal mostró neumoperitoneo y signos de diverticulitis aguda. Se intervino al paciente realizando una intervención de Hartmann.

Palabras clave: Prostatitis aguda, diverticulitis aguda, síntomas urológicos.

\section{Introducción}

La diverticulosis colónica es una patología frecuente, aumentando su prevalencia con la edad. De todos los pacientes con enfermedad diverticular, un $15-25 \%$ desarrollarán una diverticulitis aguda en algún momento de su vida ${ }^{1}$. Exponemos un caso de presentación poco frecuente de diverticulitis aguda perforada con síntomas urológicos.

\section{Caso clínico}

Varón de 72 años que acude al Servicio de Urgencias refiriendo dolor hipogástrico y genital, vómitos y fiebre de $38^{\circ} \mathrm{C}$ de 72 horas de evolución. El paciente también relataba un cuadro de disuria y dolor perineal durante la micción. Al detectarse febril, comenzó tratamiento por su cuenta, sin prescripción facultativa, con Amoxicilina/Ácido Clavu-

\footnotetext{
*Recibido el 26 de mayo de 2009 y aceptado para publicación el 17 de Junio de 2009.

Correspondencia: Dr. Jaime Ruiz-Tovar

Corazón de María, 64, 7º J. 28002 - Madrid, España.

E-mail: jruiztovar@gmail.com
} 


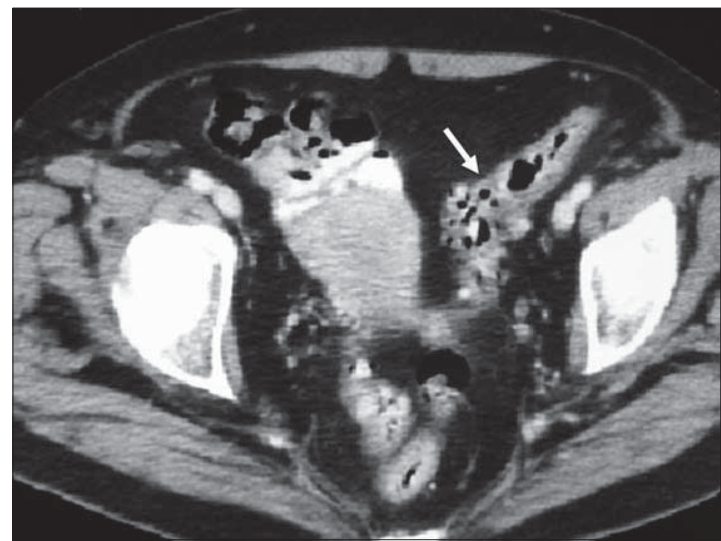

Figura 1. Engrosamiento en la pared del sigma con divertículos y afectación de la grasa regional

lánico. A la exploración física destacaba un dolor hipogástrico moderado sin peritonismo. Al tacto rectal, la próstata estaba edematosa y resultaba dolorosa a la presión, sobre todo del lóbulo izquierdo. Una analítica mostró 18.100 leucocitos $/ \mathrm{mm}^{3}$ con neutrofilia y el sedimento de orina presentaba abundantes leucocitos, células descamativas y cilindros granulosos. Se realizó una tinción de Gram de una muestra de orina, no observándose microorganismos. A pesar de la ausencia de gérmenes en orina (se asumió que tras la toma de antibiótico, el Gram y el sedimento urinario podían no presentar bacterias), el paciente fue inicialmente diagnosticado de prostatitis aguda y se inició tratamiento antibiótico intravenoso (Levofloxacino $500 \mathrm{mg} / 24 \mathrm{~h}$ ).

Al día siguiente, el paciente presentaba mayor distensión abdominal y un dolor más agudo en hipogastrio y fosa ilíaca izquierda, con signos de peritonismo a la exploración física. Una nueva analítica mostraba 24.300 leucocitos $/ \mathrm{mm}^{3}$. Se realizó una TC abdominal, observándose neumoperitoneo y signos de diverticulitis en sigma (Figura 1). Se decidió realizar una laparotomía exploradora de urgencia, en la que se objetivó la perforación de un divertículo en sigma con peritonitis fecaloidea local. Se realizó una intervención de Hartmann (sigmoidectomía con colostomía terminal en fosa ilíaca izquierda). El paciente evolucionó favorablemente y fue dado de alta al $8^{\circ}$ día de la intervención.

\section{Discusión}

La historia clínica típica de fiebre, disuria y dolor pélvico o perineal, junto con el hallazgo exploratorio de una próstata edematosa y dolorosa al tacto rec- tal y alteraciones en la analítica de orina, orientan al diagnóstico de prostatitis aguda ${ }^{2}$. Nuestro paciente cumplía todos estos criterios, exceptuando la ausencia de alteraciones en la analítica de orina, si bien, el haber estado tomando antibióticos previamente, asumimos que podría haber negativizado el gram y el sedimento de orina.

Las manifestaciones clínicas típicas de diverticulitis aguda son el dolor en fosa ilíaca izquierda con signos de irritación peritoneal, aunque pueden aparecer también náuseas y vómitos, estreñimiento o diarrea ${ }^{1}$. Está descrito que hasta un $10 \%$ de pacientes pueden presentar disuria. Las manifestaciones urológicas en las diverticulitis colónicas aparecen por las relaciones anatómicas de la flexura del colon sigmoides sobre la cúpula vesical ${ }^{3}$. Las diverticulitis agudas simulando cólicos ureterales o cistitis son más frecuentes ${ }^{4,5}$.

Actualmente existen pruebas diagnósticas que apoyan el diagnóstico de prostatitis aguda: la determinación del marcador tumoral PSA (del inglés, Prostate Specific Antigen) y la ecografía transrectal. Los valores séricos de PSA suelen estar elevados en fase aguda, disminuyendo tras el tratamiento antibiótico y la desaparición de la sintomatología ${ }^{6}$. La ecografía transrectal muestra una próstata aumentada de tamaño y edematosa, y resulta de especial utilidad para descartar abscesos prostáticos. El principal problema es que es una prueba que puede resultar dolorosa en fase aguda ${ }^{7}$. En nuestro Servicio de Urgencias no disponemos de ninguno de estos dos medios de diagnóstico, basándose este en la historia clínica, la exploración física y los resultados de las analíticas de sangre y orina.

En el caso presentado, podríamos asumir también una prostatitis aguda secundaria al proceso infeccioso colónico. Al estudiar infecciones crónicas de vejiga, se recomienda investigar una posible patología colónica causante o relacionada (diverticulitis, colitis, fístula), como consecuencia de la situación anatómica vecina de ambas estructuras. Esta recomendación también podría ser aplicable a infecciones urológicas agudas como la prostatitis.

Las infecciones no complicadas del aparato genitourinario son frecuentes y suelen resolverse rápidamente con tratamiento antibiótico, por lo que la realización de una prueba de imagen se considera habitualmente innecesaria. Sin embargo, en pacientes con factores predisponentes pueden progresar a infecciones complejas. En esos casos las técnicas de imagen permiten evaluar la extensión de la enfermedad y eventuales factores relacionados, como podría haber ocurrido en el caso presentado de diverticulitis aguda. La prostatitis aguda puede desembocar en una situación de riesgo vital cuando el diagnóstico o el tratamiento fallan. Por 
ello, podría considerarse como una infección urinaria potencialmente complicada y realizarse de forma rutinaria una $\mathrm{TC}$ abdominal u otra prueba de imagen, para evaluar el estado de la glándula, confirmar el diagnóstico y descartar eventuales complicaciones ${ }^{8}$.

\section{Referencias}

1. Jacobs DO. Clinical practice: Diverticulitis. N Eng J Med 2007; 357: 2057-2066.

2. Habermacher GM, Chason JT, Schaeffer AJ. Prostatitis/chronic pelvic pain syndrome. Annu Rev Med 2006; 57: 195-206.

3. Konvolinka CW. Acute diverticulitis under age forty. Am J Surg 1994; 167: 562.

4. Rucker CM, Menias CO, Bhalla S. Mimics of renal colic: alternative diagnoses at unenhanced helical CT. Radiographics 2004; 24: 11-28.

5. Carvalho JP. Acute diverticulitis. Primary diagnosis with ultrasonography in 4 cases presenting urologic disease (diverticulitis with urologic symptoms). Acta Med Port 1993; 6: 335-339.

6. Kobayashi M, Nukui A, Morita T. Serum PSA and percent free PSA value changes after antibiotic treatment. A diagnostic method in prostate cancer suspects with asymptomatic prostatitis. Urol Int 2008; 80: 186-192.

7. Loch AC, Bannowsky A, Baeurle L, Grabski B, König B, Flier G, et al. Technical and anatomical essentials for transrectal ultrasound of the prostate. World $\mathrm{J}$ Urol 2007; 25: 361-366.

8. Puech P, Lagard D, Leroy C, Emberton M, Illing RO, Allen C. Imaging in urinary tract infections in adults. J Radiol 2004; 85: 220-240. 